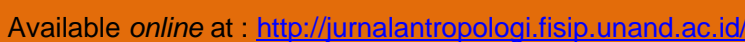 \\ Jurnal Antropologi: Isu-Isu Sosial Budaya
}

\section{TEONG NEGERI: SENTRALITAS FOLKLORE NAMA LOKAL KOMUNITAS DALAM JEJARING SOSIO-KULTURAL ISLAM-KRISTEN DI MALUKU}

\author{
Revaldo Pravasta J ulian MB. Salakory $\left({ }^{1 *}\right)$, Izak Yohan Matriks Lattu $\left({ }^{2}\right)$ \\ Rama Tulus Pilakoannu ( ${ }^{3}$ ) \\ ${ }^{123}$ Universitas Kristen Satya Wacana, Salatiga, Jawa Tengah, Indonesia.
}

\begin{tabular}{ll} 
ARTICLE INFORMATION \\
\hline Submitted & $: 08^{\text {th }}$ October, 2019 \\
Review & $: 21^{\text {st }}$ October, 2019 \\
Accepted & $: 04^{\text {th }}$ May, 2020 \\
Published & $: 1^{\text {st }}$ June, 2020 \\
Available Online & $:$ June, 2020
\end{tabular}

\section{KEYWORDS}

Teong Negeri; Folklore; Community Local Name; Socio-Cultural Networks

\section{CORRESPONDENCE}

*E-mail: 752018010@ student.uksw.edu

\begin{abstract}
A B S T R A C T
This article analysis about Teong Negeri has folklore centrality of community local name of Muslim-Christian socio-cultural network in Maluku. This study is qualitative research. Data were collected through interviews, documentary studies an observation. Methods analysis employed was descriptive qualitative. In the folklore of the village Wassu of Erihatu Samasuru (Christian), it has pela of the village of Haya Nakajarimau (Muslim) which means leader (older brother) for his three brothers, the village of Hatu Silalou (Christian) and the village of Tehua Lounusa Amalatu (Muslim). Communal narratives bind and become a link to give spirit to identity because society listen to local stories about Teong Negeri that have strong meanings, believing in each other. The four villages, in central Maluku, which are Wassu, Haya, Hatu, and Tehua, use the Teong Negeri symbol as an identity to maintain relations of kinship bond. The network that was built was challenged when the religious communal conflict happened, but the spirit towards the culture was always unheld. Teong Negeri became a symbol of central identity towards the traditional village that was able to regulate the socio-cultural system of every village in Maluku. not only for every community that has a bond of brotherhood or ethnicity. However, it becomes a universal symbol when, as a socio-cultural capital that is able to bridge the community from outside (buton migrants) based on cross-generation dialogue carried out by early generations of indigenous Maluku people with Buton migrants (migrants) in Maluku in order to have knowledge about the relationship harmonious
\end{abstract}

\section{A. PENDAHULUAN}

enulis melihat dalam kebudayaan Maluku setiap negeri memiliki Teong Negeri (nama lokal komunitas). Teong Negeri merupakan nama adat atau nama gelar yang diberikan kepada negeri adat di Maluku, pemberian nama Teong Negeri biasanya berdasarkan kepada kejadian perkara saat negeri tersebut didirikan untuk pertama kalinya. Teong Negeri ini menggunakan bahasa daerah atau bahasa asli, simbol yang secara fisik batu teong (batu pertama tanda membangun negeri) dan baileo (rumah adat negeri), yang menjadi simbol bersejarah dan mengikat setiap masyarakat yang berada di wilayah mereka tinggal bahkan menghubungkan masyarakat di luar wilayah. Akan tetapi makna Teong Negeri dengan bertumbuhnya zaman modern simbol identitas ini telah dilupakan dan sebagian dari masyarakat Maluku, tidak mengetahui tentang nama adat dari negeri mereka. menurut Cooley disebabkan oleh pengaruh kekuasaan dari zaman kolonial belanda sehingga bahasa asli di Maluku mengalami kepunahan (Cooley, 1987).

Namun berbeda dengan keempat negeri yang memiliki ikatan kultural yaitu negeri Wassu, Haya, Hatu dan Tehua yang memegang teguh kepada ikatan persaudaraan yang luhur, sehingga kepercayaan (trust) yang dibangun pada masa lampau oleh keempat negeri pela gandong yang terikat dalam hubungan jejaring sosio-kultural yang begitu kuat. Keempat negeri tersebut memiliki hal yang unik untuk menjaga relasi persaudaraan mereka yaitu dengan menggunakan pengetahuan mereka tentang Teong Negeri (nama lokal komunitas) agar jejaring sosio-kulutural (pela gandong) terlihat kokoh dan tidak tergoyahkan ketika konflik Agama (Islam-Kristen) di Maluku. semua ini tidak terlepas dari pengetahuan masyarakat (folklore) terkhususnya dalam kehidupana keempat negeri, pela gandong (Haya, Hatu, Tehua dan Wassu). Keempat negeri ini menggunakan pengetahuan 
mereka sebagai masyarakat lokal tentang pentingnya primodial bond, serta bagaimana pentingnya makna Teong Negeri untuk menjaga hubungan persaudaraan (pela gandong) pada pra sampai pasca-konflik.

Penelitian sebelumnya pada aras Global telah bank mengkaji tentang jejaring sosial (sosial network) misalnya: Fukuyama yang menjelaskan bahwa jejaring sosial dibangun berdasarkan radius kepercayaan masyarakat Cina dan Amerika Latin (Fukuyama, 2014; 2010). Robert Putnam yang menegaskan bahwa jejaring sosial memperkuat demokrasi negara demokratis seperti Amerika Serikat (Putnam, 2000). Dalam konteks Cina, Richard Madsen menjelaskan bahwa jejaring sosial berbasis budaya menjadi kekuatan masyarakat Cina, bahkan ketika dikuasai oleh Partai Komunis yang menolak demokrasi (Madsen, 2007). Di Indonesia, penelitian tentang jejaring sosial telah dilakukan oleh Najib Azca. Bagi Azca, jejaring sosial masyarakat Yogyakarta menjadi kekuatan sosial untuk membangun relasi sosial masyarakat (Mas' oed dan Azca, 2001). Jejaring sosio-kultural juga menjadi kekuatan masyarakat Maluku pasca konflik seperti yang diteliti oleh Izak Lattu dalam tulisannya, "Culture and Christian-Muslim Dialogue in Moluccas-Indonesia" dalam artikel ini membahas tentang budaya jejaring yang disebut pela, dapat dilihat pasca-konflik banyak daerah di Maluku melaksankan ritual (panas pela) yang berfungsi untuk membuat masyarakat kolektif mengingat sumpah nenek moyang untuk mencintai sampai sekarang dan mengantisipasi pertikaian di masa depan; Lattu, 2012: 45-52).

Penelitian terdahulu yang membahas tentang jejaring sosial, dan dalam artikel Lattu sendiri melihat kekuatan jejaring budaya (Pela) untuk berdialog ketika pasca-konflik. Bakri dalam artikelnya yang berjudul Resolusi konflik melalui pendekatan kearifan lokal pela gandong di Kota Ambon. Dalam tulisanya membahas tentang bagaimana kearifan lokal (Pela gandong) berperan penting dalam rekonsiliasi konflik agama yang diakibatkan karena adanya unsur politisasi (Bakri, 2015). Begitupun Hehanussa Pela Gandong merupakan model untuk kehidupan bersama dalam konteks Pluralisme Agama di Maluku. dalam tulisannya dimana pemuda agama (muslim) yang mengedepankan Nilai lokal (Pela dan Gandong), sebagai dasar budaya agar dapat berjejaring dengan saudara mereka di Kristen (Hehanussa, 2009). Berikutnya Masringor dan Sugiswati dalam artikelnya yang melihat Pela Gandong yang bagian dari pranata adat digunakan sebagai sarana penyelesaian konflik, sehingga dapat mengikat seluruh kelompok masyarakat yang terlibat konflik (Masringor dan Sugiswati, 2017). Berdasarkan beberapa penulis terdahulu sedikit memiliki perbedaan dalam artikel ini penulis melihat bagaimana pengetahuan masyarakat (folklore) tentang Teong Negeri (nama adat) negeri di Maluku yang adalah bagian dari pranata budaya digunakan masyarakat lokal untuk menjaga (jejaring sosio-kultural) pela gandong ketika konflik dan membangun rekonsiliasi komunal pasca konflik agama di Maluku. Celah tersebut yang akan penulis eksplorasi dalam penelitian tesis ini. Karena itu, tulisan ini bertujuan melihat Teong Negeri sentralitas folklore nama lokal komunitas dalam jejaring sosio-kultural IslamKristen di Maluku. dapat dilihat kekuatan jejaring Pela Gandong dari ketiga negeri sehingga ketika konflik pada tahun 2001 di Pulau Seram Selatan ketiga negeri yang memiliki hubungan pela gandong tidak terjadi konflik. Ketiga negeri ini saling melindungi satu sama lain. Terbukti salah satu dari ketiga negeri yang memiliki ikatan Pela gandong ini mayoritas Kristen, yaitu negeri Hatu yang semasa konflik tidak diserang, karena negeri ini memiliki kedua pela gandong dari negeri Islam (Negeri Haya dan Tehua) yang secara geografis ketiga negeri pela gandong tersebut berada di daerah yang sama, yaitu di kecamatan Tehoru. Dengan demikian penulisan ini akan mengkaji perihal Teon Negeri yang merupakan nama lokal telah mampu menjadi simbol yang mengitegrasi, dan memiliki peran penting dalam menjaga relasi jejaring sosiokultural (pela gandong) pada masa dan pasca konflik Maluku.

\section{B. METODE PENELITIAN}

enis dan metode penelitian kualitatif etnografi digunakan untuk memperoleh data hasil temuan di lapangan secara mendalam berdasarkan pemahaman-pemahaman para informan. Data yang diperoleh akan diuraikan dengan kata-kata menurut pernyataan informan dan kemudian akan dianalisis secara ilmiah dengan kata-kata yang melatarbelakangi perilaku informan terkait cara berpikir, berperasaan dan bertindak (Creswell, 2010). Penelitian ini akan dilakukan di pulau haruku negeri Wassu (Kristen), dengan pela gandong mereka di pulau seram negeri Haya (islam), negeri Hatu(kristen) dan negeri Tehua (islam). Penelitian ini, penulis menggunakan beberapa teknik pengumpulan data yang akan digunakan, yakni pertama, hasil data wawancara merupakan teknik dalam mengumpulkan data sehingga dapat dilakukan secara berhadapan dengan informan sehingga dapat memperoleh informasi dengan leluasa. Pertanyaan-pertanyaan yang diajukan haruslah pertanyaan yang bersifat terbuka dan tidak terstruktur yang dapat membuka pikiran informan untuk memberikan pendapat (Creswell, 2010: 267). Wawancara face to face dilakukan bertujuan sehingga peneliti memperoleh data secara langsung dari tangan pertama (Usman 
dan Akbar., 2008). Informan yang akan di wawancarai ialah para saniri dari keempat negeri pela gandong (pemimpin dalam stuktur pemerintah negeri). Kedua studi dokumenter antara lain foto-foto dan yang terkait dengan hasil penelitian (Creswell, 2010: 270). Ketiga, studi pustaka. Dalam penelitian ini, penulis akan melakukan studi pustaka guna memperoleh landasan teori melalui buku, literatur atau catatan terkait dengan penelitian yang dilakukan. Penulis akan menganalisa hasil data yang didapatkan dari hasil wawancara dan datang yang didapatkan dari lapangan secara sistematis agar mudah untuk dimengerti oleh para pembaca. Dengan demikian, akan hasil analisa akan dikaji berdasarkan emik (Huberman, 2014) masyarakat tentang Teong Negeri begitu penting bagi masyarakat Maluku tengah dalam menjaga jejaring kultural (relasi Islam-Kristen) sewaktu dan sesudah konflik.

\section{HASIL DAN PEMBAHASAN}

\section{Folklore Teong Negeri dalam kehidupan masyarakat}

$\mathrm{D}$ alam cerita rakyat ketiga negeri Teong Negeri Nakajarimau dari Negeri Haya, tidak terlepas dari kisah pertarungan antara leluhur dari Negeri Haya dengan seekor naga yang mengganggu ketentraman masyarakat. Menurut cerita, leluhur dari Negeri Haya dipercaya memiliki kemampuan khusus merubah dirinya menjadi seekor Harimau. Maka dengan keperkasaannya kemenangan dimiliki oleh leluhur dari Negeri Haya, sehingga dengan kemenangan tersebut masyarakat Haya dapat hidup dengan tentram dan damai. Dengan demikian, Teong Negeri dari Negeri Haya yaitu Nakajarimau; Naka artinya naga dan Jarimau artinya harimau, bagi masyarakat adat artinya negeri yang perkasa. Beberarapa literatur tentang folklore antara lain: menurut William Thoms folklore merupakan pengetahuan rakyat. Secara khusus, cerita rakyat ditransmisikan secara lisan misalnya bahasa, teknik berburu, dan aturan perkawinan adalah upaya memberikan pengetahuan bagi generasi penerus, Ada beberapa bentuk cerita rakyat yang dimanifestasikan dan dikomunikasikan hampir secara eksklusif dalam bentuk tertulis sebagai kebalikan dari bentuk lisan, seperti syair buku ayat, marginalia buku, epitaf, dan huruf tradisional (misalnya, surat berantai). Bagi para folklorist cerita rakyat yang ditransmisikan dari individu ke individu, sering kali secara langsung melalui kata atau tindakan, tetapi kadang-kadang secara tidak langsung. Ciri-ciri pengenal menurut Dundes folk merupakan komunitas yang memiliki identitas yang sama misalnya secara fisik tubuh memiliki kulit, rambut, bahasa, agama dan pekerjaan yang mempunyai kesamaan (Dundes, 1965 ).

Menurut William Bascom cerita rakyat (folklore) adalah jembatan antara masyarakat melek huruf dan non-melek huruf. Dia melihat folklore atau cerita rakyat berfungsi untuk memberikan sanksi dan memvalidasi lembaga Agama, sosial, politik dan ekonomi, sehingga dapat memberikan perangkat edukatif dalam mentransmisikan dari generasi ke generasi. bagi Bascom, mitos, legenda, dongeng, peribahasa, teka-teki, teks balada, lagu lainnya. Seni rakyat, tarian rakyat, musik rakyat, kostum rakyat, obat rakyat, adat, kepercayaan merupakan bagian terpenting dalam kebudayaan (Dundes, 1965: 25). Menurut Archer Taylor cerita rakyat (folklore) adalah bahan yang disampaikan oleh tradisi, baik dari mulut ke mulut atau oleh kebiasaan dan praktik. Ini bisa berupa lagu rakyat, cerita rakyat, teka-teki, peribahasa, atau bahan lain yang disimpan dalam kata-kata. Mungkin alat tradisional dan benda-benda fisik seperti pagar atau simpul, roti salib panas, atau telur Paskah; ornamen tradisional seperti Tembok Troy; atau simbol tradisional seperti swastika. Ini mungkin prosedur tradisional seperti melempar garam di atas bahu seseorang atau mengetuk kayu. Ini mungkin kepercayaan tradisional seperti anggapan bahwa penatua baik untuk penyakit mata. Semua ini adalah cerita rakyat (Dundes, 1965: 34).

Menurut pandangan Sims dan Stephens, folklore menjangkau kelompok orang yang berbagi hubungan pribadi, nilai, tradisi, kepercayaan dan bentuk pengetahuan lainnya, yang sebagian mendefinisikan mereka sebagai kelompok. folklore merupakan pengetahuan yang didapatkan dalam ruang keseharian (informal). misalnya dalam ritual adat, tindakan yang diwujudkan dalam keseharian, dan materi. Ini juga merupakan bagian dari perwujudan untuk menciptakan interaksi dalam kehidupan masyarakat, berlaku dinamis untuk menciptakan, komunikasi, dan proses membagikan pengetahuan itu dengan orang lain. folklore adalah tubuh kepercayaan tradisional, adat, dan ekspresi, yang diwariskan secara lisan (Sims dan Stephens, 2005).

Sedangkan menurut James Danandjaja sebagai penulis folklor yang berasal dari Indonesia, dalam pandangannya Danandjaja melihat kata folklor memiliki dua akar kata dalam pengertiannya yaitu majemuk, sedangkan lore yaitu sesuatu value (pesan) budaya, yang diturunkan secara lisan (oral), kepada generasi penerus. Menurutnya pertama: folklore Indonesia tidak dapat dibatasi dalam ruang yang terbatas (eksklusif), karena Indonesia Negara yang plural (beragam) dengan semboyan bhineka tunggal ika (satu dalam perbedaan), sehingga ciri-ciri fisik bukan hanya kepada orang yang berkulit putih, akan tetapi kepada masyarakat yang memiliki ciri 
fisik berkulit coklat dan hitam yang adalah bagian dari Negara Kesatuan Republik Indonesia (NKRI). Seperti di negeri Hatu awal mula pemberian nama Teong Negeri yaitu Silalou, Sila berarti satu benda yang terdiri dari bagian-bagian yang berbeda ukurannya, Lou berarti terkumpul, Silalou artinya berbeda-beda tetapi satu masyarakat Walaya, akan menjadi kekuatan masyarakat dalam menghadapi tantangan apapun dari dalam maupun dari luar. Seperti tangan dengan 5 jari berbeda tetapi lima jari ini akan bekerja sama dalam satu kepalan tangan yang kuat. sedangkan di Negeri Tehua ketika berkumpulnya Marga antara lain Sialana, Mutuu, Selano dan Latan, Kumkelo, Latua (Latue), Hayoto (Tumio) Sehingga terhimpun sebagai satu kesatuan masyarakat adat Negeri Tehua. Dengan kehadiran soa-soa (kumpulan marga) tersebut, maka mulailah mereka hidup bersama, bermusyawarahlah untuk menetukan soa (marga) Ulayo sebagai orang pertama (Tuan Tanah) di Lounusa Yamano. soa Ulayo memegang tongkat pemerintahan yang pertama. Dengan demikian nama Teong Negeri dari negeri Tehua yaitu Lounusa Amalatu artinya pulau berkumpulnya para Latu (Raja). Bagi Danandjaja Folklor berbeda dengan disiplin keilmuan lain menurutnya Folklor merupakan ilmu pengetahuan masyarakat lokal yang memiliki adat istiadat yang proses pengajaran melalui cara bercerita, nilai budaya (value) disampaikan dari generasi awal (orang tua) kepada generasi penerus (keturunan) antara lain Folklor yang bersifat fisik simbol, suatu gerakan tradisional, tarian adat budaya yang menjadi alat pengingat (Mnemonic Device). Bagi negeri Wassu yang merupakan Pela Gandong dari Ketiga Negeri Di Pulau Seram Haya, Hatu, Tehua. Berdasarkan sejarah awal masyarakat negeri ini merupakan kumpulan masyarakat yang berdiaspora dari Pulau Seram menuju ke Pulau Haruku. Maka terlihat dari nama negeri tersebut di berinama "Erihatu Samasuru" yang artinya: Weri (alangalang) Hatui (batu). Nama Erihatu dilihat berdasarkan geografis, sedangkan Samasuru artinya negeri yang berasal dari Nunusaku. Nama Samasuru dilihat berdasarkan asal-usul setiap masyarakat yang berasal dari Nusa Ina (Pulau Seram). Dapat dilihat bahwa keempat negeri ini berdasarkan kepada folklor tradisional yang tuturan ceritanya hanya ditransmisikan pada generasi tertentu. Sehingga hanya masyarakat (komunitas) dipercaya yang dapat memiliki pengetahuan ini. Danandjaja mengatakan folklor memiliki fungsi yang mampu mengikat seluruh masyarakat dalam satu hubungan kolektif, sehingga memampukan masyarakat sosial hidup dalam keharmonisan dan menciptakan pengetahuan tentang pentingnya keberagaman. folklor menjadi bagian bersama dari masyarakat kolektif tertentu. yang melalui pengalaman bersama (emosi) sehingga masyarakat terikat satu sama lain (Danandjaja, 1994). Dengan demikian penulis melihat berdasarkan kepada Teong Negeri yang adalah folklore pengetahuan bagi masyarakat lokal, selalu dijaga melalui kebiasaan bercerita (tradisi oral), upaya tradisi lisan ini berfungsi sebagai bentuk pemeliharaan budaya-budaya lokal yang ditransmisikan terhadap generasi muda, agar tetap menjunjung tinggi nilai-nilai budaya yang bersifat integrasi masyarakat.

\section{Teong Negeri sebagai Jejaring Sosio- Kultural}

Jaringan sosial adalah jaringan ikatan sosial yang mengelilingi seseorang. Analisis jejaring sosial dikembangkan dalam bidang antropologi dan sosiologi sebagai tanggapan terhadap pengamatan bahwa hubungan yang dipelihara orang tidak selalu dijelaskan dengan pola kekerabatan atau keanggotaan dalam kelompok atau kelas sosial tertentu. Menurut Agusyanto jaringan sosial begitu penting karena mampu membantu manusia agar dapat berelasi dengan semua manusia. Sehingga manusia bukan hanya berelasi dengan sesamanya (kelompok) saja, akan tetapi dengan orang di luar kelompok mereka. Baginya pengalaman setiap individu serta kebutuhannya dapat membuat manusia mampu berinteraksi dengan orang dari luar dirinya (Agusyanto, 1995: 1 ). Robert Lawang mencoba menjelaskan makna jejaring dalam modal sosial, merupakan ikatan pertalian antara individu atau kolektif masyarakat dalam sistem kepercayaan (Trust), yang saling menghubungkan membentuk hubungan sosial dalam mengupayakan satu rasa bersama, sehungga saling memperdulikan antar sesama, dengan demikian jejaring yang terikat begitu kuat dan tidak mudah putus, disintegrasi apabila menghadapi sebuah masalah. Jejaring tidaklah mementingkan diri sendiri, melainkan kepentingan masyarakat bersama, jejaring dalam sosial capital memiliki unsur menjaga dan menjembatani seluruh masyarakat agar kepercayaan terus kuat Dari beberapa literasi tentang jejaring penulis melihat bahwa dalam suatu kelompok (kumpulan individu), saling membutuhkan satu sama lain, sehingga tidak dapat berdiri sendiri. Meskipun dalam jejaring/kelompok masingmasing individu memiliki kebutuhan mereka. Akan tetapi adanya rasa nilai solidaritas yang diatur dalam kelompok demi menjaga jejaring tersebut agar tetap kuat (Lawang, 2004). Berdasarkan hasil penelitian jejaring kultural yang terjadi telah lama terjalin misalnya di negeri Haya Nama Teong di Negeri Haya (Nakajarimau), kata Naka atau Naga, ada kemungkinan perjumpaan masyarakat ketika berada di Negeri lama dengan para pedagang dari Cina pada 
abad ke 15 sebelum datangnya bangsa Eropa. Hal ini terlihat dari temuan beberapa keramik antik yang diduga berasal dari Cina pada zaman Dinasti Qing (Handoko, 2016). Sedangkan kata Harimau atau Jarimau, beberapa kemungkinan, nama lokal tersebut memiliki keterkaitan dengan perjumpaan dengan penyiar Islam dari luar. Likur Samalehu merupakan penyiar agama Islam berasal dari Arab, yang dalam jalur pelayaran melewati Buton, dan setelah itu pada tahun 1625 menuju ke Seram Selatan. Nama Teong Negeri (Nakajarimau) merupakan penghormatan terhadap kepemimpinannya yang telah memimpin serta melindungi seluruh masyarakat dari bahaya eksternal. Begitupun di negeri Wassu, Hatu Dan Tehua dimana Teong Negeri sebagai simbol yang mampu mengikat seluruh masyarakat. sedikit berbeda dengan teori jejaring oleh Barnes tahun 1954 menemukan konsep jaringan berguna dalam menggambarkan pola hubungan di sebuah desa nelayan kecil Norwegia yang tidak mudah dijelaskan berdasarkan pola kekerabatan tradisional atau kelas sosial. Memang, ketika masyarakat menjadi lebih maju dan modern dan kurang tertutup dan terikat, keuntungan dari pendekatan jaringan menjadi lebih jelas, Hal ini terjadi karena analisis jaringan membuka bidang pemeriksaan untuk semua jenis ikatan potensial dari pada membatasi oleh kami harapan yang lebih tradisional dari jenis orang yang mungkin membentuk dunia sosial seseorang. Analisis jaringan sosial adalah metode dimana ikatan orang harus memahami satu sama lain dan karakteristik ikatan tersebut diperiksa dan kemudian digunakan sebagai sarana untuk menjelaskan perilaku orang-orang yang terlibat didalamnya. Pendekatan ini tidak berkonsentrasi pada atribut orang dalam jaringan, tetapi lebih pada hubungan sosial dari satu orang ke orang lain (Scott, 2002). Disini barnes mengatakan bahwa masyarakat tradisional begitu ekslusif sehingga tidak dapat menjadi modal untuk menjembatani masyarakat secara kolektif. Dari temuan dalam artikel ini terkhususnya di negeri Haya masyarakat lokal telah belajar dalam Habitus mereka untuk mampu berelasi dengan orang dari luar. Jejaring yang dilakukan dalam tindakan keseharian saling membantu satu lain menciptakan trust (kepercayaan) mendalam dalam satu masyarakat.

\section{Folklore Teon Negeri Menjaga Jejaring Sosio-Kultural Islam-Kristen di Maluku}

Penulis melihat bahwa nama Teong Negeri begitu penting bagi mayoritas negeri adat di Maluku sebagai pranata budaya yang harus dilestarikan. Teong Negeri sendiri memiliki nilai yang kuat karena merupakan warisan yang merupakan dari simbol negeri yang memiliki nilai sakralitas yang begitu tinggi bagi masyarakat
Maluku. Menurut Pieter Pelupessy dalam penulisannya yang meneliti tentang Suku Bati di Pulau Seram, menjelaskan tentang asal tentang asal mula nusa ina atau pulau seram. Pada awal mula penciptaan Nusa Tuni atau Nusa Awal setiap negeri berasal dari suatu tempat di Nusa Ina (pulau ibu). Tempat tersebut yaitu di Gunung Murkele (Gunung Mistis). Gunung tersebut terdapat istana kerajaan Lomine yang berkedudukan di Gunung Murkele kecil, dan istana kerajaan Poyano di Gunung Murkele besar. Kerajaan Alifuru ini ditopang oleh lima kerajaan besar lainya yaitu kerajaan Silalousana atau Silalou di bagian selatan Nusa Ina (Pulau Ibu) yaitu di Supa Maraina, kerajaan Mumusikoe atau Lemon Emas di Salalea yang terdapat disebelah utara Nusa Ina (pulau ibu), kerajaan Amalia di Yamasina disebelah timur Nusa Ina (pulau ibu), dan kerajaan Nunusaku bernama Lounusa atau Tounusa disebelah barat Nusa Ina (pulau ibu), dan masing-masing istana kerajaan memiliki nama yang menjadi Teong Negeri (Pelupessy, 2012). Peran penting dari kebudayaan terlihat ketika masa konflik pada Januari 1999, kekerasan mendadak dan mengejutkan terjadi antara orang Kristen dan Muslim di provinsi Maluku, Indonesia. Sebelumnya dipandang sebagai wilayah yang stabil di kepulauan itu, ia dengan cepat menjadi tempat perselisihan antaragama yang menghancurkan. Ribuan orang terbunuh dalam spiral kekerasan selama tahuntahun berikutnya. Tidak banyak diketahui di daerah lain di Indonesia dan sebagian besar diabaikan di bawah rezim Suharto, Maluku menjadi pusat perhatian utama pemerintahan Habibie, Wahid, dan Megawati Konflik ini merupakan konsekuensi dari kebijakan Orde Baru yang mengganggu keseimbangan kekuatan antara kedua komunitas. Salah satu dari sedikit daerah dimana kedua kelompok agama itu hampir sama jumlahnya, Maluku adalah tempat kompetisi yang sunyi dan rapuh untu merebut kekuasaan antara Kristen dan Muslim. Konflik Maluku merupakan konflik yang membuat adanya disintegrasi terhadap kelompok yang berbeda secara ideologi antara Islam dan Kristen di Maluku (Bertrand, 2004).

Konflik agama di Maluku membuat kematian tercatat 8-9 ribu orang manusia tewas. Begitupun perumahan warga, gedung pemerintahan, gedung ibadah dan instansi lain tercatat, sekitar 29 ribu rumah warga terbakar, 45 mesjid, 47 gereja, 719 toko, 38 gedung pemerintahan, dan 4 bank hancur dan habis terbakar (Santosa, 2007: 201). Meskipun demikian belum mampu mengganggu stabilitas dari kohesi sosial masyarakat maluku sendiri yaitu Pela. Menurut Lattu, Pela merupakan identitas masyarakat Maluku yang diwariskan dari satu generasi ke generasi penerus yang lain dan dipelihara sebagai ingatan kolektif yang harus dipertahankan (Lattu, 2012). Menurut Ruhulesin, 
kata Pela terbagi atas tiga. Pertama, pulau Haruku misalnya negeri Pelauw, Kailolo, Kabauw, Ruhumoni dan Hulali kata pela berarti sudah, dan di Pulau Ambon misalnya Negeri Tulehu, Tengah-tengah dan Tial, Pela berarti "cukup". Ada juga Istilah "Pela nia" memiliki arti sampe jua (berhenti bertengkar). Kedua, Kata pela menurut masyarakat di pulau seram di ambil dari salah satu tradisi kakehang (suatu proses pembentukan jati diri terhadap laki-laki) yang berati saudara. Ketiga. Kata Pela artinya laha (orang tatua) yang memiliki ikatan. Sehingga kata pela di percaya berasal dari moyang dulu (para leluhur). (Ruhulesin, 2005.)

Menurut Bartels, adanya ikatan genealogi diantara klan-klan negeri sekutu (pela gandong). Dengan mengangkat sumpah, ikatan klan itu diformalkan untuk seluruh negeri dan sejak saat itu mereka dianggap sebagai satu Pela penuh. Di negeri dimana diakui adanya hubungan genealogi antarklan tapi tidak diangkat sumpah, larangan pernikahan hanya berlaku bagi klan yang berhubungan dan tidak ada kewajiban timbal balik antara negeri yang terlibat secara keseluruhan. Pela ini juga disebut adik-kakak, karena dalam ikatan ini, negeri yang didiami oleh kakak tertua dari nenek moyang yang sama mempunyai status yang lebih tinggi daripada negeri adik-adiknya (Bartels, 2017). Menurut Zamzami, kearifan lokal yang berlaku dalam komunitas adat di Indonesia menciptakan value (nilai) sebagai elemen dasar kehidupan masyarakat adat yang di aplikasikan dalam ritual adat (Zamzami dan Hendrawati, 2014.) Hal yang sama dialami oleh negeri yang berada di pulau haruku yaitu Wassu yang memiliki Pela Gandong yang berasal dari pulau Seram yaitu: negeri Haya, negeri Hatu dan negeri Tehua yang telah menjalin sebuah jejaring sejak zaman nenek moyang. Menurut Sejarah hubungan pela gandong antar keempat negeri ini berawal dari seorang kapitang (panglima perang) dari negeri Wassu (Erihatu Samasuru). Pada awalnya kapitang (panglima perang) yang bernama supele (nama panglima perang negeri wassu) ini berasal dari pulau seram, yang memiliki hubungan dengan ketiga Kapitang dari negeri Haya, Hatu Dan Tehua. Kapitang Supele (nama panglima perang negeri wassu) yang pada waktu itu melakukan perjalanan ke salah satu gunung yang bernama gunung Sembilan (Wara Siwa).

Dalam Folklore masyarakat Gunung Sembilan (Wara Siwa) merupakan tempat dimana kerajaan yang memiliki kekuatan mistis, dan tidak sembarangan orang yang bisa pergi ke gunung tersebut. Perjalanan Kapitang Supele ke gunung tersebut untuk melihat api, menurut cerita masyarakat Maluku primitif belum mengetahui api tersebut (sesuatu yang berwarna merah). Sebagai adik yang bungsu Kapitang Supele (panglima perang negeri wassu) yang menawarkan dirinya untuk pergi ke gunung itu, setibanya disana dia melihat api (sesuatu yang berwarna merah) namun kedatangannya diketahui dan dikejar. Dia pun berlari sambil membawa api tersebut dan menceburkan dirinya ke dalam air. Sambil tetap berenang dirinya tiba di salah satu tempat negeri Wassu (Erihatu Samasuru) dan sebagai titah raja dia diangkat menjadi Kapitang (gelar panglima perang) dengan marga Timisela. Sehingga ikatan persaudaraan pela gandong tersebut terdapat perjanjian antara keempat negeri yaitu negeri Wassu, Haya, Hatu dan Tehua:

1. Orang Wassu dan orang Haya, Hatu dan Tehua tidak boleh baku kawin (menikah).

2. Orang Wassu dan orang Haya, Hatu dan Tehua tidak boleh baku musuh (bermusuhan).

3. Orang Wassu dan Orang Haya, Hatu dan Tehua harus baku jaga (saling menjaga satu sama lain).

Berdasarkan penguraian diatas menurut Danandjaja folklore ditransmisikan secara lisan kepada generasi muda sebagai (mnemonic device) (Danandjaja, 1994: 2). dapat dilihat bahwa keempat negeri tersebut memiliki kesadaran kolektif terhadap kearifan lokal, menurut sulaeman dalam penulisannya yang melihat masyarakat Maluku khususnya negeri mamala memiliki kearifan lokal mencoba mengkonstruksikan makna nilai agama dan budaya dalam tradisi bakupukul manyapu (Sulaeman, 2019). Berbeda dengan Sulaeman, penulis melihat ketiga pela gandong dari negeri Wassu yang menggunkanan Teong Negeri mereka masing-masing antara lain: negeri Haya (Nakajarimau) artinya pimpinan (kakak) bagi ketiga saudaranya, negeri Hatu (Silalou) dan negeri Tehua (Lounusa Amalatu). 


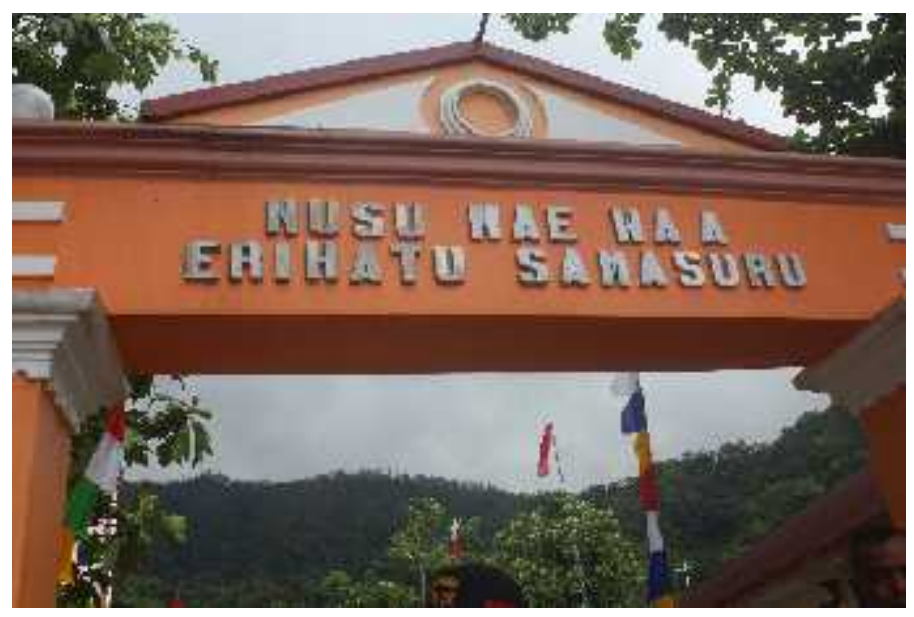

Gambar 1. Gapura: Teong Negeri Erihatu Samasuru/Wassu.

Teong Negeri merupakan simbol pengingat (mnemonic device) yang memiliki peran penting dalam mengingat memori kolektif dimasa lampau yang selalu dihormati, dijaga oleh keempat negeri yang memiliki lkatan pela gandong. Dengan demikian setiap daerah di Maluku yang terikat dalam jejaring (pela gandong) ketika konflik agama berlangsung keempat negeri ini tidak mengalami konflik. Menurut castells identitas ialah kumpulan aktor sosial yang dari padanya membentuk suatu komunitas sebagai bentuk perlawanan, dari sini adanya kesadaran kolektif untuk mempertahankan identitas (Castells, 2010).

Sewaktu konflik tahun 2001-2002 di Pulau Seram ketiga negeri yang memiliki hubungan pela gandong tinggal dalam satu teritori, salah satu negeri Kristen, yaitu Hatu tidak diserang, karena negeri ini memiliki kedua pela gandong dari negeri Islam (Negeri Haya dan Tehua) yang juga berada di daerah yang sama, yaitu di kecamatan Tehoru. Kejadian tersebut menunjukkan bahwa Teong Negeri ialah salah satu bagian dari folklore sebab menjadi simbol identitas dan mnemonic device (alat pengingat) dari keempat negeri untuk melawan isu yang menggunakan identitas agama sebagai pemicu konflik, sehingga keempat pela gandong menggunakan simbol identitas (Teong Negeri) yang memiliki fungsi untuk menjaga keharmonisan selama konflik komunal antaragama berlangsung di Maluku. Semua hal ini karena masyarakat Maluku terkhususnya keempat negeri masih mengawetkan folklore atau cerita rakyat kepada generasi penerus secara lisan. Sehingga adanya pengetahuan bagi generasi muda supaya menghormati eksistensi budaya yang menjadi identitas mereka.

Bagi keempat negeri, nama Teong Negeri memiliki fungsi untuk menjaga janji-janji para leluhur yang sehingga terwujudnya keharmonisan keberagaman agama di Maluku. Terkhususnya bagi masyarakat negeri Wassu, Haya, Hatu dan Tehua dengan nama Teong Negeri merupakan simbol penghubung bagi masyarakat yang berdiaspora, dan yang tinggal di negeri begitupun untuk menjaga relasi dengan pela gandong. Pasca konflik komunal 1999-2002, keempat negeri Wassu (Kristen), Haya (Islam), Hatu (Kristen) dan Tehua (Islam), berupaya merevitalisasi identitas mereka, dengan cara menghidupkan ikatan primordial bond sebagai upaya menjaga jejaring yang telah mengikat dalam hubungan pela gandong bagi generasi muda melalui cerita yang lisankan. Begitupun nama lokal (Teong Negeri) di Maluku merupakan identitas dari setiap negeri di Maluku. Dalam upacara adat biasanya masing-masing negeri menggunakan nama Teong Negeri atau disebut nama lokal sebagai menjadi simbol identitas dari negeri. Teong Negeri yang menggunakan bahasa asli atau bahasa lokal ini sering digunakan dalam ruang formal ketika berlangsung ritual adat, misalnya relasi-relasi ini dihidupkan sebelum konflik pada tahun 1970 perbaikan gedung gereja di negeri Wassu dan pada tahun 1980 masa kepemimpinan Raja Salakory pemasangan tiang kabah masjid Ukhuwah Negeri Haya. pertemuan ini terjadi pada 9 Desember 2009, dalam acara perayaan 100 tahun penginjilan masuk di negeri Hatu, pembangunan gedung masjid di negeri Haya pada tahun 2010 acara pelantikan raja Samalehu (gelar: Lattu Haya) dan pada tahun 2016 kembali diadakan pelantikan raja Hasan Waelisa di negeri Haya dan pada 19 oktober 2019 pelantikan raja negeri Wassu yang menghadirkan ketiga Pela Gandong Haya, Hatu dan Tehua. 


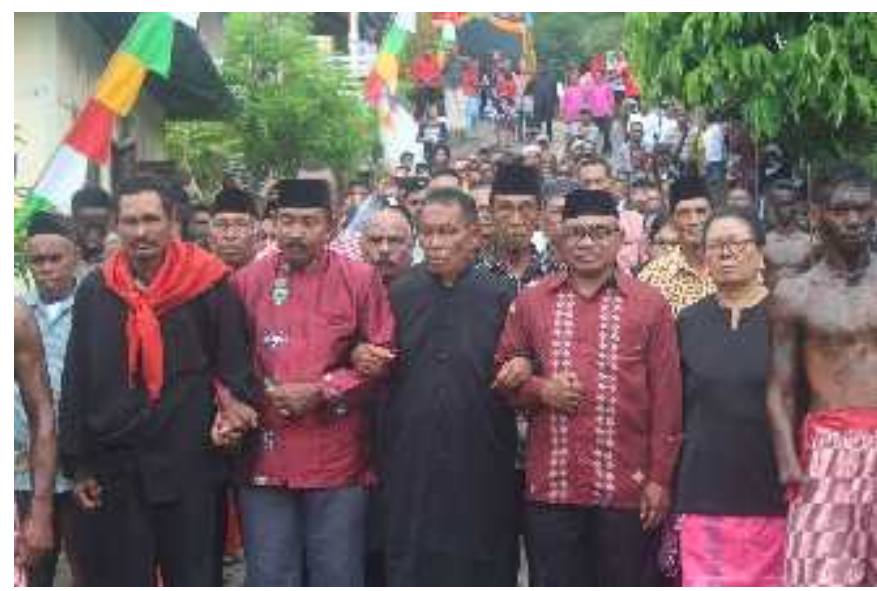

Gambar 2. Pelantikan Raja/Upu Latu Negeri Wassu (Kristen) di damping Raja Negeri Haya (Islam), Hatu (Kristen) dan Tehua (Islam) yang saling merangkul menuju baileo

Teong Negeri ini juga kemudian digunakan dalam ruang informal, seperti sapaan dalam perjumpaan sehari-hari. Penulis melihat bahwa sapaan yang di gunakan keempat negeri yang memiliki hubungan pela gandong ini, yakni: Wassu, Haya, Hatu dan Tehua menggunakannya sebagai simbol untuk menunjukkan identitas asal mereka. Menurut Eller Simbol adalah bendabenda, gambar, suara, tindakan, gerak tubuh, ucapan, dan hampir semua media lain yang "berarti" sesuatu, yang "memiliki makna" (Eller, 2007). Apalagi di Maluku sendiri pasca konflik agama lahirnya sapaan dikalangan Islam-Kristen yang memberi nilai disintegrasi antara lain: salam yang berarti orang Islam dan sarani yang artinya orang Kristen. Sehingga bagi keempat pela gandong tersebut apabila bertemu satu sama lain digunakanlah sapaan dengan Teon Negeri yang menjadi simbol identitas (mnemonic device) dari masing-masing negeri misalnya dalam intreats sehari-hari, masyarakat dari negeri Haya berjumpa dengan seorang negeri Wassu, dan memberikan sapaan Nakajarimau maka Wassu haruslah menjawab dengan Erihatu Samasuru begitupun simbol ini berlaku bagi negeri Hatu dan Tehua. Dapat dilihat Teong Negeri merupakan simbol sakral bagi keempat negeri pela gandong karena selain menjadi simbol identitas yang mampu mengintegrasi sesama, tetapi juga menjadi simbol penghargaan terhadap leluhur. Dengan demikian ketika mereka menghargai sesama (pela gandong) mereka itu bagian dari representasi penghormatan kepada leluhur (Durkheim, 2011).

Penulis melihat bahwa simbol Teong Negeri sebagai simbol yang menjaga jejaring hubungan pela gandong ini dikarenakan adanya suatu spirit terhadap identitas. menurut Theodore Malloch dalam modal sosial adanya nilai-nilai, keramahtamahan, dan norma-norma, menurutnya hal yang sama dalam spirit capital baginya spiritual adalah sumber energi moral. nilai-nilai itu menjadi sumber yang mendasar kepada kebajikan dalam membangun kepercayaan dalam suatu jaringan yang menjadi penting bagi kesejahteraan, hidup dengan kebajikan ini membuat individu memiliki, disiplin, rasa terima kasih, memiliki keberanian, ketekunan, kerendahan hati, hal ini membutuhkan kecintaan terhadap kebijaksanaan untuk bertindak di dunia (Sullivan and Flanagan, 2012).

Berdasarkan penuturan diatas terlihat bahwa nama lokal ini merupakan simbol yang dapat menjaga relasi beberapa negeri yang mempunyai ikatan persaudaraan yang berakar kepada kesadaran dari setiap individu maupun kolektif berdasarkan narasi yang di transmisikan dari leluhur ke generasi muda. Hal ini akan membangkitkan rasa kecintaan terhadap identitas keempat negeri, sehingga adanya kesadaran terhadap masyarakat memiliki rasa bersama untuk saling menjaga sesama. Penghargaan terhadap simbol Teong Negeri bukan hanya pada masyarakat yang tinggal dalam negeri akan tetapi terciptanya rasa yang mengikat terhadap identitas. Rasa identitas pela gandong ini juga di miliki oleh setiap masyarakat keempat negeri yang tinggal diluar daerah. Bermodalkan cerita dari para orang tua meskipun tinggal jauh dari daerah akan tetapi roh penghormatan terhadap ajaran ikatan Primordial itu selalu dihormati.

Penulis mencoba melihat bahwa cerita-cerita atau folklore yang ditransmisikan membuat masyarakat memiliki pengetahuan yang diimajinasikan sehingga menimbulkan rasa kecintaan terhadap pela gandong atau ikatan persaudaraan berdasarkan simbol dari Teong Negeri atau nama lokal dalam memakai bahasa daerah dari masing-masing Negeri Wassu, Haya, Hatu dan Tehua. Dalam kerangka ini, dapat dilihat bahwa Teong Negeri bukan hanya menjaga seluruh masyarakat yang mempunyai ikatan kekerabatan (bonding), tetapi dapat menjadi simbol yang mampu menjembatani (bridging) setiap masyarakat yang heterogen (para pendatang) yang 
tinggal di daerah setempat. Penulis menemukan adanya temuan yang berbeda dengan konsep jejaring sosial yang melihat masyarakat mampu membangun jejaring individu memiliki kebutuhan tersendiri (ekonomi), sehingga mampu bekerja sama dan berinteraksi dengan orang dengan orang lain. jejaring sosial terlihat begitu kompleks, diukur dari homogenitas masyarakat (usia, kelas sosial, agama). Seperti yang disampaikan Barnes yang mengatakan bahwa jejaring sosial dilihat dari adanya sistem kelas dan adanya sistem hirarki yang dibentuk dalam mengatur pola kehidupan masyarakat di norwegia, penulis melihat bahwa teori jejaring sosial begitu ekslusif karena hubungan sosial yang terjalin karena adanya unsur kesetaraan yang tidak berlandaskan kepada kesadaran melainkan atas kepentingan dari individu dalam satu jejaring.seperti pandangannya Durkheim yang menyebutnya Solidaritas organik yaitu jaringan yang terikat atas pembagian kerja pada masyarakat modern. Begitupun Alexis De Tocqueville dalam pandangan terhadap masyarakat aristokrasi yang melakukan hubungan timbal-balik yang adalah bagian dari hukum kemasyarakatan; dan tuntutan kewajiban sosial ini dan bukan karena urusan kemanusiaan. Kaum aristokrasi hanya melakukan kewajiban membantu sebagai tuan dan budak, akan tetapi tidaklah dengan ketulusan hati, sebagaimana manusia yang membantu manusia lainnya (Tocqueville, 2005).

Menurut Putnam modal sosial memiliki dua unsur yaitu mengikat (bonding) dan menjembatani (bridging), lebih bersifat inklusif terhadap masyarakat diluar jaringan. Dirinya berpendapat modal sosial bukan hanya kepada kelompok jaringan yang memiliki ikatan kekerabatan (bonding), tetapi mampu berinteraksi dengan kelompok jaringan lain untuk membangun suatu kepercayaan (Putnam, 2000). Bridging sosial adalah suatu modal yang melihat ikatan yang renggang, dan memiliki celah sehingga mampu menjembatani untuk menengahi masalah dalam struktur jaringan (Putnam, 2000: 22). Berdasarkan temuan penulis melihat di negeri Haya sendiri, terdapat para pendatang dari Sulawesi, yaitu masyarakat Buton yang Sudah berada 70 tahun bermukim negeri Haya.

Meskipun mereka adalah pendatang, namun mereka ikut berpartisipasi dalam kehidupan kekerabatan bersama dengan masyarakat Haya misalnya acara pelantikan raja di Negeri Haya dan Negeri Wassu 19 oktober 2019 adanya bantuan-bantuan material yang di sumbangkan demi kelancaran kegiatan tersebut. Tidak hanya itu, mereka juga menghargai negeri-negeri yang memiliki hubungan pela gandong dengan negeri Haya tempat mereka tinggal. Masyarakat Haya sendiri memandang mereka sebagai bagian dari negeri tersebut sejak zaman dahulu pada abad ke 17. Sejak saat itu para pendatang telah berada dalam sistem sosial masyarakat di negeri Haya, karena itu mereka perlu menghormati kebudayaan di negeri tempat mereka tinggal. Hal ini dapat dilihat bersama ketika adanya kegiatan pencarian dana yang dilakukan oleh negeri Wassu (Erihatu Samasuru). Masyarakat Buton juga ikut berpartisipasi bersama-sama sebagai bagian dari masyarakat negeri Haya (Nakajarimau).

Penulis melihat berdasarkan temuan pertama Teong Negeri memiliki makna yang kuat karena mampu menjadi simbol sentral yang mampu menjaga ikatan primordial. Fungsi dari Teong Negeri dapat menjaga ikatan jejaring sosiokultural antarsesama (pela gandong) sebagai modal sosial, kedua menjaga sistem kohesi sosial sehingga dapat menjembatani relasi-relasi masyarakat yang berbeda (Buton) untuk saling berinteraksi dalam kehidupan sosial yang telah lama di jalin dari para orang tua (Bridging Society). Ketiga simbol Teong Negeri sebagai bukan hanya sebagai Mnemonic Device (tradisi lisan) bagi setiap masyarakat homogen (ikatan Pela Gandong) akan tetapi mengkisahkan tentang keharmonisan antara masyarakat pendatang yang telah bergenerasi di daerah tempat mereka tinggal. Sehingga dapat dilihat bahwa keharmonisan yang ditunjukan bukanlah sesuatu yang dipaksakan, akan tetapi karena masyarakat yang menjaga narasi-narasi damai, untuk menjauhkan mereka dari gangguan dari luar yang bersifat memecah belah, Interaksi dalam keseharian yang di hidupi akan memperkuat jaringan masyarakat. Dengan demikian Teong Negeri dilihat sebagai simbol yang inklusif terhadap keberagaman dan sebagai simbol yang berguna dalam menghilangkan stereotype masyarakat asli di Maluku tentang para pendatang sebagai salah satu aktor atau kelompok menciptakan konflik agama di Maluku. Teong Negeri juga merupakan simbol eksistensi dalam mempertahankan jejaring sosio-kultural yang mampu mengikat dan menghubungkan segala perbedaan mulai dari wilayah, agama, dan etnis di Maluku agar hidup damai, harmonis dan saling percaya (trust).

\section{KESIMPULAN}

$T$ eong Negeri merupakan simbol identitas bagi negeri-negeri di Maluku yang menggunakan bahasa daerah, setiap negeri selalu dikenal dengan nama lokal mereka, sehingga dapat menjaga jejaring sosio-kultural yang mampu menghubungkan mereka dengan daerah yang lain dalam ikatan pela. Dalam cerita rakyat negeri Wassu Erihatu Samasuru, memiliki pela negeri Haya (Nakajarimau) kakak tertua, bagi ketiga saudaranya, negeri Hatu (Silalou) dan negeri Tehua (Lounusa Amalatu). Dari 
pengertian masing-masing negeri menunjukan bila keempat negeri tersebut terikat dalam hubungan pela gandong. Teong Negeri dapat memberikan spirit terhadap kesadaran identitas, dikarenakan masyarakat mendengarkan cerita lisan. Teong Negeri dilihat memiliki makna yang kuat, saling percaya satu sama lain. sehingga bagi keempat negeri di Maluku tengah Wassu, Haya, Hatu dan Tehua menggunakan simbol identitas Teong Negeri untuk menjaga eksistensi hubungan relasi ikatan kekerabatan (Pela Gandong). Jejaring sosio-kultural yang dibangun mendapat tantangan ketika konflik komunal berbasis agama, akan tetapi spirit terhadap budaya selalu dijunjung tinggi.

Beberapa hal tentang Teong Negeri antara lain: Teong Negeri memiliki beberapa hal penting masyarakat adat di Maluku antara lain: Teong Negeri merupakan simbol yang menghubungkan antara masyarakat adat dengan leluhur (orang tatua) yang sangat mereka hargai. Nilai (value) yang menjadi dasar masyarakat adat untuk selalu menghargai cerita kehidupan para leluhur awal yang membangun tempat tinggal, ternyaman bagi generasi penerus dapat hidup dengan nyaman. Para leluhur telah memberikan pengetahuan sosial-kultural bagi penerusnya agar menghargai wilayah yang telah diberikan, ada suatu harapan besar para leluhur bagi generasi penerus supaya tetap utuh dalam satu kesatuan masyarakat adat, yang berpegang teguh pada janji, norma-norma, sehingga masyarakat dapat berelasi dengan sesama. Teong Negeri dilihat sebagai simbol yang begitu penting karena merupakan bagian dari local wisdom masyarakat adat terkhususnya bagi keempat negeri yang memiliki ikatan pela gandong. Seperti yang di kemukan dilistone simbol merupakan tanda untuk saling mengenal, begitupun teong negeri yang merupakan simbol yang memiliki makna untuk menjaga kohesi sosio-kultural yang menjadi identitas lokal masyarakat adat.

Teong Negeri menjadi sakral bagi keempat negeri ini karena adalah bagian dari mnemonic device yang dilisankan. Teong negeri memiliki nilai-nilai sakral karena berbicara tentang sejarah awal mula negeri ini didirikan sampai pada konteks saat ini teong negeri digunakan dalam ritual-ritual adat misalnya upacara pertemuan pela gandong; pelantikan raja, kegiatan yang berkaitan dengan keagamaan, dan sebagai salam untuk memperkenalkan dari mana dirinya berasal. Teong Negeri menjadi suatu simbol identitas sentral terhadap negeri adat yang mampu mengatur sistem sosio-kultural setiap negeri di Maluku. bukan hanya bagi setiap masyarakat yang memiliki ikatan persaudraan atau sesama etnis. Akan tetapi menjadi simbol universal ketika, sebagai modal sosio-kultural yang mampu menjembatani masyarakat dari luar (migran buton) berdasarkan kepada dialog lintas generasi yang dilakukan generasi awal masyarakat Maluku penduduk asli dengan penduduk pendatang Buton (migran) di Maluku agar memiliki pengetahuan tentang hubungan yang harmonis .

\section{E. UCAPAN TERIMAKASIH}

$\mathrm{P}$ enulis ingin mengucapkan terimakasih kepada dosen pembimbing Izak Y. M. Lattu dan Rama. Tulus. Pilakoannu yang telah membantu dalam menyelesaikan artikel ilmiah ini hingga terbit. Penulis mengucapkan terimakasih kepada Program Magister Sosiologi Agama, Universitas Kristen Satya wacana.

\section{DAFTAR PUSTAKA}

Bakri, H. (2015, January ,). Resolusi Konflik melalui PendekatanKearifan Lokal Pela Gandong di Kota Ambon. (The POLITICS:Jurnal Magister IImu Politik Universitas Hasanuddin, Volume 1, Number 1), 51-60.

Bartels, D. (2017). Di Bawah Naungan Gunung Nunusaku: Muslim-Kristen Hidup Berdampingan Di Maluku Tengah; Jilid I, . Jakarta: : Kepustakaan Populer Gramedia.

Bertrand, J. (2004). Nationalism and Ethnic Conflict in Indonesia. New York: Cambridge University.

Castells, M. (2010). "The Power Of Identity: . United Kingdom: Second Edition With A New Preface" Willey Black Well, .

Cooley, F. L. (1987). Mimbar dan Takhta. Jakarta: Pustaka Sinar Harapan.

Creswell, W. J. (2010). Research Design: Pendekatan kualitatif, Kuantitatif dan mixed. Yogyakarta: : Pustaka Pelajar.

De Tocqueville. Alexis. (2005). Tentang Revolusi, Demokrasi, dan Masyarakat. (Jakarta: Yayasan Obor Indonesia, )

Dundes, A. (1965). The Study Of Folklore,. United States of America:: Prentice-Hall. Inc. Engelwood Cliffs, N. J, . 
Durkheim, E. (2011). The Elementary Form of The Religious Life, Sejarah Bentuk-Bentuk Agama yang paling dasar. Jogjakarta: IRCiSoD.

Eler, J. D. (2007). Introducing Anthropology of Religion: Culture To The Ultimate. NewYork:: Routlged. .

Fukuyama, F. (2010). Trust Kebajikan Sosial dan Penciptaan Kemakmuran. . Penerbit Qalam.

Fukuyama, F. (2014). The Great disruption, Hakikat Manusia dan Rekonstruksi Tatanan Sosial. Penerbit Qalam.

Handoko, Wuri .(2016, Juli). Arkeologi Sejarah Islam Di Pesisir Selatan Pulau Seram Maluku Tengah. Kapata Arkeologi, Volume 12 Nomor 1, 79-90.

Hehanussa. Jozef M. N. (2009). PELA DAN GANDONG: Sebuah Model Untuk Kehidupan Bersama Dalam Konteks Pluralisme Agama Di Maluku. Gema Teologi, Vol 33 No 1 ), $1-15$.

Huberman, M. B. (2014). Qualitative data analysis: An expanded sourcebook (3rd ed.).Qualitative data analysis: An expanded sourcebook (2nd ed.). . London: Sage Publication.

James., D. (1994). Folklore Indonesia, IImu Gossip, Dongeng dan lain-lain. . Jakarta: : Pustaka Utama Grafiti.

John, S. (2002). Social networks: Critical concepts in sociology,. London and New York:: Taylor\&Francis.

Lattu, I. Y. (2012). Culture and Christian-Muslim Dialogue in Moluccas Indonesia. , Interreligious Insight, Vol. 10, No. 1:, 45-52.

Lawang, R. M. (2004). Kapital Sosial Dalam Perspektif Sosiologik-Suatu Pengantar,. Jakarta: FISIP UI Press, Fakultas IImu Sosial dan IImu Politik Universitas Indonesia.

Martine., S. C. (2005). Living Folklore, An Introduction to the Study of People and Their Traditions. Utah State : University Press Logan.

Mas' oed, S. M. (2001). Social Resources for Civility and Participation: The case of Yogyakarta. Indonesia. Jurnal The Politics of Multiculturalism: pluralism and citizenship in Malaysia, Singapore and Indonesia, ., 119-140.

Masringor. Julia dan Sugiswati. Besse (2017). Pela Gandong Sebagai Sarana Penyelesaian Konflik. Jurnal Perspektif, volume 22. No 1 thn , 66-79.

Pelupessy, P. J. (2012). Esuriun Orang Bati. Salatiga: Disertasi, Program Pascasarjana Studi Pembangunana-Universitas Kristen Satya Wacana.

Putnam, R. D. (2000). Bowling Alone: The Collapse in Revival of American Community. New York: : SIMON \& SCHUSTER.

R., Agusyanto. (1995 ). Dampak Jaringan Social Dalam organisasi: Kasus PAM Jaya, . DKI Jakarta.: Universitas Indonesia,.

Richards., M. (2007). Democracy's Dharma : Religious Renaissance and Political Development in Taiwan. Berkley :: University Of California Press.

Ruhulesin, J. C. (2005.). Etika Publik: menggali dari tradisi Pela di Maluku, . salatiga-jawa tengah: Disertasi, Fakultas Teologi Universitas Satya Wacana,.

Pelupessy, Pieter J. Esuriun Orang Bati, (Disertasi, Program Pascasarjana Studi

Pembangunana-Universitas Kristen Satya Wacana, 2012), 126-127.

Santosa, B. A. (2007). "Peran Media Massa dalam Mencegah Konflik", . Jurnal ASPIKOM, Volume 3 Nomor 2,, 201.

Sulaeman, M. M. (2019). Konstruksi Makna Bakupukul Manyapu Bagi Masyarakat Mamala di Maluku. Jurnal Antroplogi: Isu-Isu Sosial Budaya, 16 (1), doi.org/10.25077/ jantro.v21.n61.p72., 37-48.

Sullivan, O. M. (2012.). Spiritual Capital: Spirituality in Practice in Christian Perspective, . united kingdom: Ashgate Publishing Limited .

Usman. Akbar., U. H. (2008). Metodology Penelitian Sosial. . Jakarta:: Bumi Aksara.

Zamzami, L. \&. (2014.). Kearifan Budaya Lokal Masyarakat Maritim Untuk Upaya Mitigasi Bencana di Sumatera Barat. Jurnal Antroplogi: Isu-Isu Sosial Budaya, 16 (1), 37-48. doi:10.25077/jantro.v16.n1.p, 37-48. 